\title{
LEITURAS DO MITO E A ESCOLA DE CAMBRIDGE
}

Hugo Francisco Bauzá

Face ao racionalismo do século XVIII, que fustiga o mito devido aos componentes supostamente irracionais que esse possa comportar, os quais, para esta vertente de análise, dificultam tanto o progresso social quanto o desenvolvimento do espírito, surge, por oposição, o parecer de Giambattista Vico, que propõe uma nova leitura do mito e, com ele, do pensamento mítico.

Segundo este estudioso, em uma primeira fase da humanidade, os homens teriam desenvolvido uma sabedoria poética na qual o mito cumpre um papel destacado, à margem do que poderíamos chamar a lógica aristotélica, razão porque este tipo de discurso deve ser estudado dentro dos marcos de uma Ciência Nova (1744), e, por certo, com um método igualmente novo. Para Vico, o mito já não é o produto do demoníaco, nem erro, nem natureza enganadora, mas sim emergente de uma qualidade humana - a imaginação - que possui uma natureza específica, que difere da razão.

De acordo com esta leitura, os conteúdos do mito não podem ser julgados sobre a base de questões racionais stricto sensu, uma vez que a imaginação possui uma modalidade expressiva própria, assim como uma verdade específica que nos inclina preferencialmente para o metafísico e o religioso.

Neste sentido, Bemejo Barrera sublinha "a valorização do mito como uma forma de conhecimento de certo modo superior à razão, ao considerar poética é capaz de alcanzar a compreensão de uma série de verdades muito profundas que a razão não é capaz de entender" (Barrera, 1988, p. 22) razão porque vê a Vico como precursor das questões que no século XIX sustentarão o Romantismo, e será precisamente por esta causa que suas opiniões somente serão compreendidas e valorizadas a partir deste século.

Hugo Francisco Bauzá. Universidad de Buenos Aires - CONICET.

Tradução de Francisco Marshall. 
Os mitos merecem ser estudados pelas diversas ciências - antropologia, filosofia, arqueologia, história... - mas que não devem ser considerados nem como símbolo, metáfora nem alegoria, mas sim - ainda que pareça tautológico - somente como mito, isto é, como um relato tradicional, transmitido oralmente de geração em geração, e que na maior parte dos casos remete a sucessos extraordinários situados na transhistória.

Com o Romantismo, este tipo de discurso será objeto de estudo histórico e sua análise, em consequência, passará a ser inseparável da classificação e consideração tanto cronológica quanto filológica das fontes escritas e arqueológicas.

Nesta ordem, Friedrich Creuzer, em seu Simbólica e mitologia dos povos antigos, especialmente do grego (1810-1812), nos proporciona um dos primeiros esforços para alcançar um tratamento sistemático novo do mito e do pensamento mítico. Creuzer considera que a humanidade primitiva havia usado uma linguagem de caráter simbólico com o propósito de expressar os problemas cruciais que atingem ao homem.

Poucos anos mais tarde, em 1825, Karl Muller publica seus Prolegomena zu einer wissenschaftlichen Mythologie, em que se vale de um método histórico rigoroso na hora de empreender a análise dos mitos, aos quais reduziu a um tipo de memória sui generis de meros acontecimentos históricos; contudo, a pesar de seu esforço marcadamente explicativo, não termina de definir o que vem a ser o mito. O essencial de seu método consiste em considerar que esta forma de linguagem está enraizada na história e que, em conseqüência, não se pode empreender seu estudo à margem desta ciência.

Vinculado com esta linha de análise encontra-se Johann Jacob Bachofen. Este jurista - autor de um trabalho insubstituível, Das Mutterrecht, 1861 - amplia as idéias de Muller, concebendo o mito como fenômeno cultural. Para isto, parte da noção germânica de Geist - espírito -, assinalando que o mito, mais do que enquadrado no contexto histórico em que surgiu, deve ser situado no sistema ideológico de que procede e ao qual, conseqüentemente, pertence.

O mito não evocará então acontecimentos supostamente acontecidos, como o pretende imediatamente a escola historicista, mas nos alertará sobre aspectos culturais dos diferentes povos, destacando seus contatos, similaridades e divergências. Ademais, Bachofen amplia o conceito de historicidade, dado que considera que é histórico não somente o que pode ter ocorrido, mas também o que pode ter sido pensado, por meio do que chega "a uma construção da história desde um ponto de vista interior" (Barrera, 1988, p. 26). 
Bachofen, atento ao sistema hegeliano, percebe diferentes estádios no processo histórico; deste modo, sublinha, em primeiro lugar, uma fase de hetairismo (hetaíra, cortesã), em que os homens dominavam as mulheres e estas, como autodefesa, devem ter criado ou uma sociedade matriarcal que exercia o poder e participava da guerra - o mito das Amazonas é um traço palpável desta perspectiva -, ou ter instaurado o matrimônio e as leis sobre a base de um direito materno fundado em laços de sangue, no afetivo e no religioso. Também neste aspecto o mito grego mostra vestígios da tensão agônica entre duas formas de vida - a matriarcal e a patriarcal - e a luta pelo exercício do poder.

Quando na primeira parte da Orestéia de Ésquilo Clitemnestra enfrenta Agamêmnon em um diálogo ríspido, além de uma queixa de ordem privada de uma mulher para seu marido, infiel e sacrílego, é a substituição de uma ordem matriarcal - atenta à procriação, ao afetivo e ao religioso - por uma patriarcal que privilegia a força e o poder e cujo único modo de operar é o combate. Bachofen libera o mito do marco rigoroso do acontecimento histórico, para situá-lo, por outro lado, no horizonte menos rígido do sociológico e do cultural.

Nesta linha de exegetas se encontra Georges Grote, pioneiro na hora de nos proporcionar pautas metodológicas ainda hoje válidas no que respeita ao estudo de mito e ritual. Grote, em seu History of Greece (184656), ao ocupar-se do chamado período "arcaico" da história deste povo - i.e., anterior à $1^{a}$ Olimpíada $(776 \text { a.C. })^{1}$-, lança mão da comparação etnográfica com as populações primitivas contemporâneas da Índia então muito estudadas pelos ingleses -, o que lhe ajuda a compreender determinados comportamentos e pautas deste período lendário da Hélade. Outro fato notável de seu trabalho é ter insistido na necessidade de não se separar o mito do campo da oralidade - ou seja, como expressão verbal de uma sociedade que ainda não conhecia o recurso da escrita e que, portanto, tem formas diferentes de codificar e processar a informação -; assim, Grote propõe que os mitos devem ser compreendidos não desde nosso ponto de vista de seres letrados, mas sim desde o possível ponto de vista de seus ouvintes ágrafos ${ }^{2}$. Deste modo, busca neles suas próprias razões, assim como uma lógica própria.

Quanto à oralidade, que referi como modalidade natural do mito, convém apontar que a passagem desta formulação para a escrita acontece como com o registro escrito dos poemas homéricos, por obras dos Pisistrátidas, em que, ao deixar o campo do oral, de passa de uma forma in uiuo para uma in uitro. Ao encapsular, tanto a estes relatos míticos quanto às referidas epopéias, tem-se a sensação de que se restrin- 
ge o alento vital característico de uma recitação sustentada na voz do declamador, problema sobre o qual, em nossos dias, insiste Florence Dupont (1994).

Sobre a linha historicista do citado Karl Muller articula-se a Escola histórico-filológica alemă, que, no século XIX, pôs ênfase no fato de que o mito grego deve ser estudado em si mesmo, prescindindo da comparação etnográfica. Para os membros desta Escola - Hermann Usener e Ulrich von Wilamowitz-Möllendorf, entre os mais destacados -, não existe praticamente nenhum laço que permita vincular os gregos da Antigüidade com os "selvagens" dos tempos modernos. Na lente destes pensadores, o que caracteriza aos gregos é sua quota de racionalidade, da qual - estimam - carecem nossos coetâneos primitivos; o que no mito grego possa haver de irracional, entendem ser de procedência forânea, concretamente, do Oriente helenizado.

Tais idéias, em seu momento, receberam a oposição de pensadores como Erwin Rohde $(1894)^{3}$ e, mais adiante, Walter Otto, este último, especialmente em Dionysos. Mythos und Kultus $(1933)^{4}$, para não citar o caso de Nietzsche, com a publicação de Die Geburt der Tragödie ${ }^{5}$ em 1872, e a polêmica que esta obra suscitou junto a filólogos como o citado Wilamowitz. Estudos recentes, em particular os do helenista irlandês Eric Robertson Dodds ${ }^{6}$, colocaram em relevo aspectos discutíveis do reducionismo da citada Escola histórico-filológica; assim, por exemplo, quando o professor Dodds explica como fenômenos gregos como o do dionisismo, ou de algumas religiões de mistérios ou o de alguns cultos iniciáticos praticados por este povo - sobre os quais hoje contamos com os valiosos trabalhos de Walter Burkert ${ }^{7}$-; estes ritos evidenciam que entre os gregos, além da referida quota de racionalidade, existia também uma linha de pensamento que não desatendia a consideração do irracional.

Face à citada pretensão historicista, é lícito que nos perguntemos: qual é a datação de um determinado mito? Qual é sua primeira versão? E ainda no caso de se contar com uma "suposta" primeira versão, nada nos impede de pensar que tenha havido outra anterior que não tenha chegado até nós, tema já percebido pelos primeiros mitógrafos - cf. Eliano de Preneste (século II d.C.) ou a Biblioteca do pseudo-Apolodoro.

Toda vez que se considera um mito, como com razão sustenta LéviStrauss, não se deve atender somente a uma determinada variante tida supostamente como a mais antiga, mas sim à soma de todas as versões conservadas, do mesmo modo como não constituem a árvore as suas distintas partes - tronco, galhos, copa... -, mas sim a visão de conjunto de todos os seus componentes; ampliando este conceito, hoje, de maneira 
semelhante, fala-se, a partir de uma perspectiva simbólica, de uma arborescence mythique ${ }^{8}$.

Ademais, na hora de abordar os mitos gregos, não contamos com sua forma genuína, que era a oral, mas sim com seu sucedâneo literário que, de certo modo, é uma uariatio espúria, pois foi subtraída da recitação no banquete, simpósio ou outras reuniões conviviais, restando-lhe o caráter performático inerente a essa declamação e que era, certamente, o traço consubstancial de sua natureza. Conseqüentemente, conhecemos tais relatos não em sua modalidade prístina, mas sim já transpostos ao campo da literatura, da dramaturgia ou mesmo através de testemunhos iconográficos. Essas diferentes variantes expressivas devem ter deformado a realidade mítica, de onde a dificuldade que se apresenta ao pretendermos compreender e objetivar esse tipo de relatos, aos quais, ademais, se desnaturaliza também toda vez que se procura racionalizá-los, ao adscrevê-los à esfera do lógos, o que em essência é um contra-senso.

Advertido da falácia desta pretensão, Wilamowitz-Möllendorf, em seu memorável Der Glaube der Hellenen - 'A fé dos gregos' -, parte da idéia a priori fundada em uma fé ou adesão sentimental: os deuses estão aí (Barrera, 1988, p. 32), isto é, que toda vez que se pretenda entender a mitologia ou o ritual gregos é mister aceitar essas idéias e crenças que para o heleno constituíram um fato indubitável; tal é o que sustenta igualmente Walter Otto em seu Teofanía ${ }^{9}$. Esta é a condição sine qua non proposta por este estudioso na hora de considerar o mito grego. Contudo, Wilamowitz não pode subtrair-se do historicismo de sua época, uma vez que postula que o mito é um ente que nasce em um determinado momento da cultura, em seu caso, nos primeiros séculos da Hélade.

Para este helenista, o mito é válido tanto por seus valores no campo do literário, quanto como via de acesso à compreensão do fenômeno religioso entre os gregos; despreocupa-se, por outro lado, face ao fato de que o mito possa encerrar também uma semanticidade de ordem política, social ou cultural ou que inclusive possa implicar outros códigos, tal como a antropologia tem revelado nas últimas décadas, em especial através de sua corrente estrutural.

Nesta linha de análise se filia Martin Persson Nilsson ${ }^{10}$. O professor Nilsson aborda as origens da religião grega - em suas fontes minóica e micênica - lançando mão não apenas de vestígios arqueológicos, mas também encarando uma análise sociológica de diversas lendas heróicas. Sua exegese aponta para um problema chave quanto ao estudo dos mitos e rituais: a utilização política dos mitos nos marcos da história 
grega, muito especialmente no toca ao papel dos oráculos e das famílias vinculadas com o rito eleusino.

A decifração do sânscrito - a língua clássica da civilização bramânica - deu nascimento à lingüística comparada e, por extensão, à mitologia comparada segundo a concebe Max Muller. O mérito da lingüística comparada foi haver proporcionado um método, logo utilizado com proveito por outras ciências.

O afã comparatista não apenas levou a se confrontar corpora mitológicos de diferentes culturas, mas também a se propor vinculações entre mitos e ritos; desta última comparação nasceu o interesse por estabelecer a cronologia entre mito e ritual. Neste sentido, a síntese mais acabada que pretende articular ritual e mito é a proposta pela Cambridge School. Esta escola estava integrada, entre outros, por Jane Hellen Harrison ${ }^{11}$, Francis McDonald Cornford ${ }^{12}$, o australiano Gilbert Murray ${ }^{13}$ - professor em Oxford mas filiado academicamente aos "ritualistas" de Cambridge - e por A. B. Cook, autor do monumental estudo sobre Zeus; estes scholars atuam em uma época vitoriana, que entendia o mito como algo arcaico e primordial. Todos eles originariamente eram helenistas profissionais.

Filólogos e antropólogos durante décadas não conseguiram pôr-se de acordo sobre a prioridade cronológica do mito ou do ritual; para aqueles, o mito precede o rito; para estes, de modo inverso. Ademais, os filólogos clássicos opuseram-se encarniçadamente a que a cultura grega fosse julgada com pautas proporcionadas pelo estudo de culturas "selvagens", e a disputa entre ambos pareceres chegou a alturas inesperadas.

Contudo, o resultado mais importante alcançado pelos membros desta Escola radica em ter tomado consciência de que a tão célebre sophrosyne 'serenidade' - o bastão inquestionável dos filólogos em prol da defesa da ratio helênica - era o termo luminoso de um largo processo, em cujos pilares existiam formas obscuras primitivas - mitos e rituais ctônicos e mistéricos - que atualizavam a tensão entre o dionisíaco e o apolíneo sustentada por Nietzsche e que hoje, mercê de estudos comparativos do campo antropológico, ninguém questiona. Em seu empenho por encontrar uma religiosidade grega anterior à dos deuses olímpicos, mostraram-se complacentes em utilizar sugestões da mitologia comparada; assim, "historicismo, e ao mesmo tempo abertura para os estudos contemporâneos de sociologia e antropologia caracterizaram esta atitude, tão diferente do cassicismo winclelmaniano ou do conservadorismo corrente do helenista profissional" (Gual, 1987, p. 107). Estes scholars conseguiram demonstrar muitas das instituições vertidas décadas antes por F. Nietzsche e E. Rohde 
e logo reafirmadas por Walter Otto, no que concerne aos aspectos sombrios e irracionais de um transfundo religioso de base ctônica ${ }^{14}$.

Os "membros" da Cambridge School pretenderam, com fortuna desigual, unir os resultados da filologia clássica com os avanços da antropologia e da sociologia, então ainda verdes. No caso da antropologia, apoiaram-se sobre as questões de Sir James Frazer, vertidos em The Golden Bough - O ramo dourado ${ }^{15}$ - com a qual este estudioso fundou o comparatismo etnográfico, para o qual o sentido de um mito ou de um ritual só é compreensível se estudado com relação a outro análogo de uma cultura diferente. Segundo Frazer, a humanidade teria passado por três estádios - mágico, religioso e científico - onde cada um deles substitui - e anula - ao anterior, o que, rigorosamente, não é exato. Tal leitura, como salta aos othos, fundamenta-se no Cours de philosophie positive inaugurado em la Sorbonne por Auguste Comte em 1826; nestas lições, o filósofo distingue, na organização da sociedade, três momentos: o primeiro de caráter teológico e militar; o segundo, de caráter metafísico e legista e o terceiro, de caráter positivo e industrial; neste último, segundo Comte, os homens - deixando de lado os estádios anteriores - se esforçam por descobrir as leis efetivas que regem os fatos, valendo-se para isso da observação e do raciocínio.

Os membros da Escola de Cambridge combinam as teses dos filólogos com a antropologia avant la lettre sustentada por Frazer e com os estudos de sociologia, então incipientes, desenvolvidos por Émile Durkheim (cf., em especial, Les formes élémentaires de la vie religieuse, Paris, 1925). Nesta vertente de análise, os ritualistas anglo saxões abordam o mito e o rito helênicos cotejando-os com os dados que sobre seus coetâneos primitivos lhes proporcionava a corrente antropológica; em tal projeto, a atenção estava dirigida a povos ágrafos.

Para esta Escola, o mito é um estádio secundário da cultura, dado que é a explicação, mediante palavras, do ritual primitivo; este, por sua parte, não seria outra coisa senão os diferentes atos levados a cabo pelos seres humanos com o propósito de obter alimento, clima favorável, boas colheitas ou outros benefícios. Nessa ordem, amparados na exegese de Frazer, vêem a religião destes povos como um conjunto de ritos - a maior parte das vezes de natureza agrária -, não carentes de componentes mágicos.

Anos mais tarde, Jane Harrison, influenciada por Émile Durkheim, considerará os ritos, os mitos e outras formas do religioso como fenômenos sociais que têm como meta prioritária a manutenção da coesão do grupo. 
Quanto ao valor que a Cambridge School confere à antropologia na hora de considerar mitos e ritos, B. Malinowski, com sua experiência de campo com os Trobriand, apontou: "O antropólogo - e somente ele entre os muitos participantes no torneio mitológico - tem a única vantagem de consultar ao selvagem sempre que sente que suas doutrinas se tornam confusas e que o fluxo de sua eloqüência argumentativa seca. $O$ antropólogo não está atado aos escassos restos de uma cultura, como tabletes quebrados, textos opacos ou inscrições fragmentárias. Não precisa preencher imensas lacunas com comentários volumosos, mas baseados em conjecturas. O antropólogo tem à mão o próprio fazedor do mito" (1974, p. 122).

Em nossos dias, as idéias preconizadas pelos cultores da Escola de Cambridge perderam valor quanto ao tópico da prioridade do ritual face ao discurso mítico, e hoje são defendidas por muito poucos estudiosos; penso, por exemplo, em Fontenrose ou em Walter Burkert ${ }^{16}$.

Os ritualistas de Cambridge se equivocaram, por exemplo, quando pretenderam explicar a tragédia a partir da análise de um ritual primitivo. Inobstante algumas imprecisões conceituais, mercê de seus aportes quanto à interconexão de saberes, os estudos sobre mito e rito são considerados na atualidade como parte integrante de uma vasta trama cuja urdidura só pode ser inteligida com o auxílio indispensável de uma variedade de ciências - a filologia, a antropologia, a lingüística, a história e, entre outras, a arqueologia -; tal, por exemplo, a linha de análise que preconiza Gilbert Durand, articulada em torno do conceito de l'imaginaire. Os que praticam este tipo de leitura - J. Thomas, J.-J. Wunenburguer ou A. Moreau, entre os mais conhecidos, fizeram aportes importantes na hora de voltar a considerar a relação entre mito e ritual.

\section{REFERÊNCIAS BIBLIOGRÁFICAS}

Malinowski, B. Magia, ciencia, religión, (versión española de A. Pérez-Ramos), Barcelona, Ariel, 1974.

Barrera, Bermejo. Grecia. El mito griego y sus interpretaciones, Madrid, Akal, 1988 , p. 22.

\section{NOTAS}

1. Cf. a cronologia de Grote; atualmente, situa-se o período arcaico aproximadamente entre esta $I^{2}$ Olimpíada e as Guerras Greco-Pérsicas (490-479 a.C.) (N.T.). 
2. Tema que nos é hoje muito familiar, após os estudos de M. Parry, B. Gentili, E. A. Havelock, W. J. Ong, D. Page, entre os estudiosos mais importantes; para um status quaestionis, remeto a Jack Goody, La domesticación del pensamiento salvaje, versión española de M. V. García Quintela, Madrid, Ed. Akal, 1985.

3. Quanto a Rohde, cf. Psiche. La idea del alma y la inmortalidad entre los griegos (versión esp. de W. Roces), México, FCE, 1948 [original: 1894]

4. Tenho em mãos a versão francesa de Patrick Lévy: Dionysos. Le mythe et le culte, París, Mercure de France, 1959. Publicaçāo original: 1933.

5. A polêmica se havia desatado três anos antes, com a Aula Inaugural de $\mathrm{Ni}$ etzsche na cátedra da Universidade de Basilea. Ad hoc, cf. Nietzsche, F., Homero y la Filología Clásica. Lección inaugural. Basilea 1869, Presentación y trad. de L. Jiménez Moreno, Madrid, Ed. Clásicas, 1995.

6. The Greek and the Irracional, Los Angeles, University of California Press, 1962; há tradução espanhola de María Araujo: Los griegos y lo irracional, Madrid, Alianza, 1980, assim como brasileira: Os Gregos e o Irracional, São Paulo, Ed. Escuta, 2001.

7. Cf., entre outros, Structure and History in Greek Mythology and Ritual (Univ. of California Press, 1979) e Greek Religion (versão inglesa de John Raffan, Harvard University Press, 1985), Les cultes à mystères dans l'Antiquité (tradução do ingles por B. Deforge y L. Bardollet, París, Les Belles Lettres, 1992); cf. também Antigos Cultos de Mistério, São Paulo, Edusp, 2000.

8. Conceito ideado por J-.J. Wunenburger -sobre o paradigma da arbre philosophique proposto por C. Jung-; ad hoc cf. F. Monneyron y J. Thomas, Mythes et littérature, Paris, PUF, 2002, pp. 29-31.

9. Teofanía. El espíritu de la antigua religión griega (versão espanhola de J. J. Thomas), Buenos Aires, EUDEBA, 1968.

10. Cf. seu Geschichte der griechischen Religion. O leitor espanhol conta com duas obras do mesmo M. P. Nilsson que condensam o vertido em seu monumental Geschichte, elas são: Historia de la religiosidad griega (versão espanhola de Martín Sánchez Ruipérez), Madrid, Gredos, 1969 e Historia de la religión griega (versão espanhola de Atilio Gamerro), Buenos Aires, EUDEBA, 1961.

11. Cf. Themis, Cambridge, 1912 (veja-se especialmente a $2 \mathrm{a}$. ed. -Cambridge, 1927- com um "Excursus on the ritual forms preserved in greek tragedy" do profesor Gilbert Murray) e seu Prolegomena to the Study of Greek Religion, e, mais tarde, seu Epilegomena to the Study of Greek Religion (Cambridge, 1921).

12. Ad hoc remeto a De la religión a la filosofia (versión española de A. PérezRamos), Barcelona, Ariel, 1984, onde estuda os vínculos assaz complexos e, em ocasiões, contraditórios entre experiência emocional e pensamento científico ou, em outros termos, entre mythos e lógos e, na mesma linha, Antes $y$ después de Sócrates (versão espanhola de A. Pérez-Ramos), Barcelona, Ariel, 1981 . 
13. Cf. seu Four Stages of Greek Religion.

14. Pode ampliar-se esta perspectiva em Emily Vermeule, La muerte en la poesía y en el arte de Grecia (1979), versão espanhola de J. L. Melena, México, FCE, 1984, pp. 21-86.

15. A primeira edição, em dois volumes, é de 1890; a edição "monumental"en doze volumen - apareceu entre 1907 e 1914. Da primeira edição existe a versión espanhola de E. y T. Campuzano, México, FCE, 1944.

16. Cf. Structure and History in Greek Mythology and Ritual, já cit., cf. espec. pp. 35-58. 